\title{
Attitudes of Professional Muslim Women in Saudi Arabia regarding Wearing the Abaya
}

\author{
C.A. DeCoursey ${ }^{1}$ \\ ${ }^{1}$ Social Sciences and Humanities, College of the Marshall Islands, PO Box 1258 Majuro, Republic of the Marshall \\ Islands $\mathrm{MH}$ \\ Correspondence: C.A. DeCoursey, Social Sciences and Humanities, College of the Marshall Islands, PO Box 1258 \\ Majuro, Republic of the Marshall Islands MH. Tel: 692-625-3394. E-mail: DrChristinaAnn2015@mail.com \\ Received: March 7, 2017 \\ Accepted: March 27, 2017 \\ Online Published: May 10, 2017 \\ doi:10.5539/ach.v9n2p16 \\ URL: https://doi.org/10.5539/ach.v9n2p16
}

\begin{abstract}
Clothing choices create a "semiotic sparkle" for the individual, and convey meaning to viewers. In a global world, interpretations may differ, if wearer and viewer are from different cultures. This is the case for the hijab, or required Muslim dress for women, which has been profoundly ideologised. This study explores how young professional Saudi women understand the abaya, the long outer robe, as a fashionable article of clothing. Corpus data was analysed using Appraisal techniques. Positive results indicate they focus on visual details, appreciate its enabling both comfort and elegance, and perceive design-diversification according to social identities, activities, contexts and roles. They view wearing the abaya as culturally authentic, more than a religious duty. Negative results focused on hot textiles in summer, movement hindrance, and cleanliness.
\end{abstract}

Keywords: abaya, hijab, fashion, Muslim women, Saudi Arabia, attitude analysis, Appraisal analysis, subjectivity, corpus linguistics, systemic functional linguistics

\section{Introduction}

Clothes produce meaning through the interaction of wearer and viewer. Individuals layer choices, which are interpreted by viewers. Muslim women's dress is ideologically marked in the western world. It can appear so within Islamic cultures as well, due to the regulations for female dress. Muslim dress requirements have also shaped global haute couture for decades (Coleridge, 1989). Yet discussion of hijab, the long robe with headscarf, is found more often in the political than the style news (Lewis, 2015). Relatively little research has explored its popularity among Muslim women, in terms of fashionability. Most studies have concentrated on Muslim women living in western or liberal Arab contexts, used small participant groups, and used a paradigm of tension between adornment and modesty (Zine, 2006; Sobh et al., 2008; Al-Qasimi, 2010; Siraj, 2011). This article uses Appraisal analysis to explore what young professional Saudi woman say about the abaya, as a fashionable item of clothing.

\section{Literature Review}

Clothing is symbolic, across human cultures (Barthes, 2006). The many details found in clothing are socially invested with meaning (Attfield, 2000). Wearers and viewers experience clothing as convey identity and emotion, through these design minutiae (Entwhistle \& Wilson, 2001). Design details connect wearers to their society through encoding elements of class, gender and material subculture (Barnard, 2002). They position wearers to participate in social, work and leisure activities, characterise the wearer's relationship to established codes of behaviour, and exhibit ideological stance (Crane, 2000). Contemporary dress is highly subjective, offering opportunities to express the self through multiple detail variations (Garot \& Katz, 2003). Fashionable dress is assembled through a process of bricolage, which produces a "semiotic sparkle" of exciting aesthetic and social meanings (Breward, 2000). Young people are especially tuned into the visual, material and procedural symbolisms of uniforms, work clothes, luxury and global brands (Purdy, 2004). Dressing is their way of constructing, reflecting on, and reconstructing their identities (Crossley, 2001). Still, there has been little focus on young Muslim women's fashion sense.

Clothing also reflects social norms, in cut and decoration (Barnes \& Eicher, 1992). "Visual cues and codes provide ideals for how people perceive themselves ... Many of these codes consolidate the bedrock of culture they live in" (Morris, 2006, p. 13). Cultural contexts shape the design details of fashionable clothing, and the meanings 
attributed to them (Kaiser, 1997). Different cultures communicate different meanings through these material symbols, and interpret each others' clothing differently (Craik, 2003). Few items of clothing have been so ideologised by other cultures as the hijab. But many contemporary analyses do not represent Muslim women, and the authentic semiotic sparkle Muslim dress provides them.

Interpretations of hijab often depend on whether interpreters are Muslim or not (Bullock, 2002). Western media tend to interpret the abaya as symbolising subjugation (Ajrouch, 2007), exclusion from society (Meer, Dwyer, \& Modood, 2010) religious oppression (Maira, 2009) and failure to assimilate culturally (Williamson, 2014). Within Islamic discourse, discussion of women's dress often focuses on the issue of modesty (El-Guindi, 1999). Qur'anic modesty injunctions require women to wear loose, opaque clothing covering the entire body to conceal its outline and any expression of sexuality. But the exact design of clothing which fulfils these requirements is not prescribed, and history attests different designs (Arthur, 1999). Diverse designs have arisen globally, for abayas (Lindholm, 2013). There is little research into what conservative Muslim women themselves think about the design of the abaya.

Women in the Kingdom of Saudi Arabia (KSA) are legally required to wear the abaya, with the shayla or rectangular head scarf, in public (Lindholme, 2010). Traditional dress has offered a vehicle through which this conservative society has struggled against modern consumerist values (Abu Odeh, 1993). So, Saudi dress requirements reflect national identity as much as religious observance (Sobh et al., 2009). But oil wealth has encouraged aspirational consumerism, with personal adornment being a normal focus of attention for Saudi youth (Alsharek, 2008). Clothing produced by global luxury brands and iconic western and multinational chains are widely available in Saudi shops (Lindholm, 2014). Trends originating in London and Paris are found in Saudi malls within a few weeks (Gole, 2002). Muslim designers quickly take up these patterns and looks (Gibson, 2000). Therefore, the abaya has acquired connotations of wealth, throughout the Gulf region (Abaza, 2007). Accessorised with jewellery, watches, glasses, shoes and purses, abayas denote status and prestige (Moors, 2011). The $21^{\text {st }}$-century abaya is adorned with beads, sparkles, mirror panels, crystals, appliques, lace and embroidery, and incorporates calligraphy, slogans and logos. It has various necklines, and can appear composed of an upper and lower segment in the manner of a woman's business suit. It comes in many colours, is cut asymmetrically, emulates styles from kimonos to sportswear, and can be made from a vast range of textiles, from fleece-lined winter wear, to practical jersey, to acid-etched jacquard. Abaya design in KSA appears vibrant and diverse. This paper explores linguistic patterns in the attitudes of young professional Saudi women about this design exuberance.

Being required to wear an abaya does not mean Saudi women relinquish decision-making in their lives. KSA has a young population, with over $30 \%$ of its 27 million aged $0-14$ years, and a further $15 \%$ aged $25-20$ years, of whom $82 \%$ are urbanised, and 35\% receive tertiary education (Forstenlechner and Rutledge, 2011). Women make use of KSA's highly developed retail and tele-banking system (Al-Ashban and Burney, 2000), with greater credit card uptake among women than men (Abdul-Muhmin and Umar, 2007). About $73 \%$ of Saudis report computer ownership, and $83 \%$ report regular internet connectivity (SACITC, 2008). Cell-phone ownership is ubiquitous among Saudi women, who tend to be early-adopters of technology (Al-Meshal and Almotairi, 2013). Decades of pressure to improve their employment prospects means that many work as entrepreneurs (Zamberini, 2011). Others are employed in the public sector (Economist, 2002). Women use gendered architecture to their benefit, in schools and universities, shopping malls, restaurants, spas and parks (Sadi and Saricimen, 2010). About $75 \%$ of the female population is married but unemployed, with shopping a significant leisure activity (Rambo et al., 2009). These women own more than $30 \%$ of brokerage accounts and $40 \%$ of family businesses (Al-Kahtani et al., 2006). A lower birth rate and increased use of contraceptives is found among educated women (Rashad, 2000). Purchases of beauty products are increasing among Saudi women (Khraim, 2011).

This study explores the subjective attitudes of female Saudi undergraduate towards the abaya as a fashionable item of clothing. Research questions included: How positive and how negative are young professional Saudi women about the abaya? How do they see its benefits and drawbacks? Do they in fact perceive it as fashionable, and if so, what regularities can be found in how they express this? How and to what degree do they view the abaya as having cultural and religious significance, and how do they understand the interaction between fashion and modesty?

\section{Method}

Qualitative data was taken from 146 female Saudi undergraduates, native Arabic speakers who had passed IELTS 5.0, or TOEFL 500/667, indicating advanced English proficiency. All were majoring in professional fields: the sciences, medicine, engineering and business. Data was collected as part of undergraduate composition and communication courses, but participation was optional, to ensure elicitation of genuine personal opinion. Participation was excluded from the regularly-assessed syllabus components, to minimise impacts from participants writing what they believed their teachers wanted to hear. Participants were asked to write a brief 
personal opinion of about 200 words, in response to a simply-worded prompt: "In your opinion, what are the advantages and disadvantages of abayas, as a fashionable item of clothing?" This kind of comparative task is familiar, being frequently incorporated in tertiary composition curricula. The prompt required participants to interpret the four semantic components via their personal experience (Block, 1998). Writing personal opinions elicits greater subjective language than conventional academic genres such as essays (Ramanathan and Kaplan, 2000).

Participant opinions were aggregated into a corpus, and Appraisal analysis used to analyse it. Content analysis was not used, as it cannot access the emotional dimensions of personal responses (Pang and Lee, 2008). For example, take the realisation:

I think it is considered elegant and formal. Basically, the abaya gives the Saudi woman a chance to express herself. As an illustration, you can wear a formal black abaya with small delicate details or even a turquoise-striped white abaya that has silver layers of lace. This makes the process of choosing your abaya an exuberant experience filled with fashionable decisions and choices.

Content analysis would produce a metric for content components ("stripe", "lace") and associated attributes ("elegant", "formal"). Appraisal analysis, by contrast, taxonomises aspects of subjective stance - emotions such as cheer ("exuberant") and confidence ("I think"), appreciations of qualities ("elegant", "formal"), judgments of ability ("you can wear", "personal decisions and choices") and of normativity ("it is considered", "Basically", "the Saudi woman"), all of which may be positive or negative. This generates a more detailed understanding of the attitudes of a specific population.

Attitude analysis is used in forensic studies of stance, evidentiality and deception, as well as in opinion-mining in marketing, (Yang et al., 2007). Individual written or spoken realisations of attitude may be aggregated into a corpus to identify regularities within the subjective attitudes of a specific participant group (Thompson, 2004). Attitude analysis offers the greatest linguistic delicacy in taxonomising realisations of positive and negative, direct and indirect attitude (Halliday and Matthiessen, 2004). "Appraisal theories of emotion have gained widespread acceptance in the field of emotion research" (Kuppens, Van Mechelen, Smits, De Boeck, \& Ceulemans, 2007, p. 689). Derived from systemic functional linguistics, these methods were used in this study, to taxonomise realisations of subjective attitude (Halliday, 1994; Martin, 1995).

When expressing personal opinions, people choose from an extensive range of possible words and phrases (Martin \& Rose, 2008). Neurolinguistic research indicates that emotion is fundamental to the expression of subjectivity, with many of the words that represent emotions corresponding to particular brain states (Pavlenko, 2002). Basic emotions are shared across cultures, and encoded in all languages (Wurm \& Vakoch, 1996). Polarity is a fundamental attribute of emotion, and expressions of attitude may be placed on a negative-to-positive cline (Bednarek, 2006). All languages also include resources allowing users to express emotion indirectly (Martin and White, 2005). Psycholinguistics represents the direct and indirect lexicons as system networks of semantic categories and subcategories (Fontaine et al., 2013).

System networks are constructed from the linguistic resources available in the English language (Halliday, 1994). Appraisal analysis selects and sorts attitudinal lexicogrammar into 24 possible semantic classes, each located within one of three sets: Affect, Judgment and Appreciation. Affect includes the categories Dis/inclination, Un/happiness, In/security, and Dis/satisfaction, which are further defined by several subcategories (Scherer et al., 2001). Affect underlies both Judgment and Appreciation, which rework feelings indirectly as propositions about persons, events, situations and objects. Judgement includes positive/negative evaluations of people, events and situations. For example, "The dark colour abaya is too hot in the summer" reworks a negative personal feeling of displeasure as a statement about the abaya and the Saudi climate. The subcategory Social esteem includes realisations evaluating normativity, capacity and tenacity, where Social sanction includes realisations evaluating veracity and propriety. Appreciation comprises positive/negative evaluations of objects outside the self (Eggins, 1994). For example, "Abaya style has developed over the past years and become more fashionable" reworks a positive feeling of pleasure as a statement about abaya fashion trends. The Appreciation set includes semantic categories for reactions to the qualities ("It resembles a posh gown") or impacts ("walking up the stairs or running fast in it is troublesome"), composition ("It instantly offers a composed and put-together appearance") and valuation ("The abaya incorporates the Arabic culture into its designs like adding Arabic calligraphy, which gives an authentic look"). The Attitude system may be seen in Figure 1. 


\begin{tabular}{|c|c|c|c|}
\hline SYSTEM & SET & CATEGORY & SUBCATEGOR \\
\hline ATTITUDE & Judgment & $\begin{array}{l}\text { Dis/inclination } \\
\text { Un/happiness } \\
\text { In/security } \\
\text { Dis/satisfaction } \\
\text { Social esteem } \\
\text { Social sanction } \\
\text { Reaction } \\
\text { Composition } \\
\text { Valuation }\end{array}$ & $\begin{array}{l}\text { fear } \\
\text { desire } \\
\text { misery } \\
\text { antipathy } \\
\text { cheer } \\
\text { affection } \\
\text { disquiet } \\
\text { surprise } \\
\text { confidence } \\
\text { trust } \\
\text { ennui } \\
\text { displeasure } \\
\text { interest } \\
\text { pleasure } \\
\text { normality } \\
\text { capacity } \\
\text { tenacity } \\
\text { veracity } \\
\text { propriety } \\
\text { impact } \\
\text { quality } \\
\text { balance } \\
\text { complexity } \\
\text { worth }\end{array}$ \\
\hline
\end{tabular}

Figure 1. The Attitude System

Appraisal system networks "are not arbitrarily posited", but reflect the convergence of linguistic and psychological paradigms of emotion (Bednarek, 2009, 150). Their increasing resemblance strengthens their validity (Elfenbein \& Ambady, 2002). Machine-tagging of attitude is well-established within computational linguistics (Read and Carroll, 2010). Concordances for specific languages are created through supervised classification tasks in combination with statistical machine-learning approaches (Pang et al., 2002). The semantic areas used in attitude analysis are easiest for software to identify (Read \& Carroll, 2010). This study used the software CorpusTool (CT), which incorporates these system networks and generates a polarity measure (O’Donnell, 2008).

\section{Data}

The task generated a corpus of 34,107 words, in 2392 sentences ( $\mathrm{m}=14.26$ words, $\sigma=0.69)$. The corpus contained 3,393 realisations of subjective attitude, of which $288=8.49 \%$ realised Affect, $1410=41.56 \%$ realised judgments, and $1695=49.96 \%$ realised Appreciations. Attitudinal density was 99.48 per thousand words. While the task had been designed to elicit positive and negative realisations equally, the corpus contained $2791=82.26 \%$ positive, compared to $602=17.74 \%$ negative realisations. Of the 24 Attitude subcategories, realisations in 6 positive and 5 negative subcategories together comprised $2496=73.56 \%$ of all realisations. These are ranked in Figure 2:

Appreciations of reaction to the qualities of abayas was by far the most frequently-realised semantic subcategory, among both positive and negative attitudes. Positive ("colourful", "beautiful", "lovely", "appeal", "classy", "creativity", "gorgeous", "stunning", "striking", “formal”), and negative ("not colourful”, "gets dirty", "poor quality", "plain", "bad", "ugly", "doesn't fit") realisations together comprised 1375=40.52\% of all attitudes realised. Judgments of Social esteem-capacity were frequently-realised, both positively ("can", "able to", "effortless", "convenient", "useful, "expertly") and negatively ("limiting", "cannot express", "inexpressive", "does not fit"), comprising $715=21.07 \%$ of all attitudes realised. Judgments of Social esteem-normality were also frequently-realised positively ("different", "special", "original", "variety", "trendy", "trending", "normal", "familiar"), and negatively ("excessive", "the same", "not the same", "strange"), comprising $418=12.31 \%$ of all attitudes realised. Frequently-realised subcategories found in the positive but not the negative dimension of the corpus include Judgments of Social sanction-propriety ("must", "have to", "should", "required", "properly", "be careful to"), Appreciations of Valuation-worth ("important", "key", "crucial", "critical", "main point", "significant", "profound") and Feelings of Dis/satisfaction-pleasure ("like", "liking", "pleased", "satisfied"). Frequently-realised subcategories found in the negative but not the positive dimension of the corpus include 
Appreciations of Reaction-impact ("hot", "heat", "hassle", "snagging", "trip", "stumble", "fall”, "accident") and Judgments of Social esteem-tenacity ("keep on", "always have to").

Table 1. Frequently-realised positive and negative Attitudinal subcategories by rank

\begin{tabular}{clllrrr}
\hline & POSITIVE & & & & & \\
\hline RANK & SET & CATEGORY & SUBCATEGORY & N & \%POS & \%ATT \\
1 & Appreciation & Reaction & quality & 1080 & 38.70 & 31.83 \\
2 & Judgment & Social esteem & capacity & 672 & 24.08 & 19.81 \\
3 & Judgment & Social esteem & normality & 361 & 12.93 & 10.64 \\
4 & Judgment & Social sanction & propriety & 167 & 5.98 & 4.92 \\
5 & Appreciation & Valuation & worth & 132 & 4.73 & 3.89 \\
6 & Affect & Dis/satisfaction & pleasure & 98 & 3.51 & 2.89 \\
& & & 1964 & 87.41 & 57.88 \\
& & & & & \\
& & & & & & \\
RANK & SET & CATEGORY & SUBCATEGORY & $\mathrm{N}$ & $\%$ NEG & \\
1 & Appreciation & Reaction & quality & 295 & 49.00 & 8.69 \\
2 & Appreciation & Reaction & impact & 113 & 18.77 & 3.33 \\
3 & Judgment & Social esteem & normality & 57 & 9.47 & 1.68 \\
4 & Judgment & Social esteem & capacity & 43 & 7.14 & 1.27 \\
5 & Judgment & Social esteem & tenacity & 24 & 3.99 & 0.71 \\
& & & & 532 & 88.37 & 15.68 \\
\hline
\end{tabular}

\section{Discussion}

Despite a task designed to elicit positive and negative realisations equally, attitudes realised were more positive than negative by a factor of about 4 . Thus, young professional Saudi women are clearly positively-disposed towards the abaya as a fashionable item of clothing.

Three subcategories were frequently-realised both negatively and positively: quality, capacity and normality. That is, the data shows that young professional Saudi women focus overwhelmingly on the specific qualities of abayas. They realised this subcategory about twice as frequently as the next most frequently-realised subcategory, capacity, and about three times more frequently than the third most frequently-realised subcategory, its socially conventional character. The subcategory quality is associated with discussion of aesthetics, based on visual perception (Martin and White, 2004). Many specific qualities of abayas were noticed, including sleeve size and cut; colour; the addition of frills, appliques, motifs, embroidery, lace, crystals, and beads; various specific textiles; tailored and self-designed as compared to off-the-rack abayas; and specific abaya designers and shops. Further, young Saudi women judge abayas according to how well they embody their expectations for abayas as a normative element of their experience. Judgments of self-esteem in the area of normality include realisations about exceptional or ordinary, special or average, usual or unusual, different-good or different-bad an item is. People use their own cultural norms and experiences, in making such judgments. Overall, then, young professional Saudi women's frame of reference for the abaya as a fashionable item of clothing is culturally local, and they find this sufficiently diverse and engaging.

Participants were not hesitant to discuss their negative views of abayas. Here also, it was specific qualities they criticised, particularly hot textiles in summer and the tendency of abayas to snag on various objects. The abaya's status as a legally or religiously-mandated garment was not at issue; realisations of the culturally-traditional and religiously-proper status of abayas were overwhelmingly positive ( 167 of $170=5.98 \%$ of realisations), and the frequency of these realisations was low, and only about $1 / 6$ as frequent as discussions of the specific qualities of abayas. This suggests that young professional Saudi women accept the abaya, do not feel any negative sense of being compelled to wear it, but are critical of some aspects of it.

We can understand these better, by exploring some examples. The examples below contain multiple realisations in various subcategories of Attitude. Only one kind has been underlined, to highlight the subcategory discussed.

\subsection{Appreciations: Reaction-Quality}

Grammatically, the Reaction subcategories correspond to mental processes of perception, and are the closest to emotion of any outside of the Affect set (Eggins, 1994). That is, a realisation such as "Its black silky material is 
slimming, comfy and keeps you warm" reworks personal feelings of pleasure as visually-perceived attributes of the abaya ("slimming", "comfy"). In "What I like about Abayas is how easy they are to wear, and how classy they look. In addition to the different styles and colors of the Abaya, ladies can be unique and represent their selves", the terms "looks", "styles" and "colours" respond to visual perceptions, where "classy", "unique" and "represent their selves" rework those responses as qualities of the abaya.

The reworking of personal feeling, mainly positive and sometimes negative, as perceived qualities of the abaya can be seen in these examples:

1) Abayas are creative $(+v e)$ with different cuts, shapes, colors and fabrics. The Abaya is not just a piece of black fabric anymore.

2) An abaya in, my opinion, is an extremely fashionable $(+v e)$ piece of cloth that can be a great $(+v e)$ addition to one's closet. Since it is black in colour, wearing an abaya can make a female look more elegant $(+v e)$ and classy $(+v e)$. Not only that but also, the black colour can make one look thinner $(+v e)$.

3) The color black doesn't compliment all skin tones, resulting in women looking pale(-ve) or not as prepossessing(-ve).

Frequently-mentioned specific qualities of abayas included ease $(127=3.74 \%$ Attitude, $11.76 \%$ Appreciation:Reaction-quality), an attractive means of covering up an imperfect appearance underneath $(93=2.74 \%$ Attitude, $\quad 8.61 \% \quad$ Appreciation:Reaction-quality $), \quad$ comfortableness $\quad(81=2.39 \%$ Attitude, $\quad 7.50 \%$ Appreciation:Reaction-quality), and convenience ( $43=1.27 \%$ Attitude, $3.98 \%$ Appreciation:Reaction-quality), as in these examples:

4) A key pro of the abaya as a fashion item is ease $(+v e)$ and tidiness $(+v e)$. It provides an easy $(+v e)$, quick $(+v e)$ cover for a mismatched outfit, instantly with the help of delicate $(+v e)$ designs and patterns.

5) One of the best $(+v e)$ things about wearing an abaya is not worrying about what to wear underneath it. For instance, I could be wearing pyjamas all day and I won't have to worry about changing when I want to go out, because no one will know what I'm wearing under my abaya.

6) Personally, I find the abaya very convenient $(+v e)$ when one doesn't necessarily want to dress up in public. It's a great $(+v e)$ way to cover up that slouchy look no one outside the room needs to see. For example, sweatpants don't feel taboo under the abaya.

7) The wrong cut and shape will make you uncomfortable even though abaya is all about comfort(+ve).

This shows that young professional Saudi women have a pragmatic attitude towards the abaya as a fashion item. They like the visually attractive qualities of fashionable abayas as an outer layer, but also like the option of comfortable clothes underneath. They appreciate the convenience offered by a publically presentable abaya, when the outfit underneath is less so. This view is culturally consonant with Muslim views of privacy as highly desirable (Kadivar, 2003).

\subsection{Judgments: Social Esteem-Capacity}

Judgments of Social Esteem construe our positive and negative attitudes about persons and events, standards and values, in our social networks. They are most often shared informally as part of oral culture where such matters are the subject of chat, opinion and gossip (Eggins \& Slade, 1997). Attitudes in this subcategory contained a high frequency of positive, but not negative realisations of capacity ("can", "able to", "have the ability to", "capable of", "the capability to"). English expressions of ability entail imagined potentialities routinely instantiated in action (Panther \& Thornburg, 1999). These expressions connect the speaker to existential states characterised by potentiality, probability and aspiration, realising the speaker's belief about their future states of affairs based on their past experiences, regular motivations and acquired capabilities (Stack, 2012). For example, "I can wear my comfy clothes underneath" both reflects the writer's past experiences, regularities in what the writer wants to do, and the probability that the writer will do so again. Capacity focused on self-expression in $114=16.96 \%$ positive and $8=18.60 \%$ of realisations in this subcategory, as in example 8 :

8 . The best thing about the abaya as a fashion item is how you can $(+v e)$ make a statement by wearing it. You $\underline{\text { can }}(+v e)$ show your style and be creative, by choosing the right colors and the perfect design that complement your body the best, the abaya has the ability $(+v e)$ to be unique and outstanding.

Capacity focused on the freedom to wear comfortable or unfashionable clothes underneath it, in $87=12.95 \%$ of positive and $2=4.65 \%$ of realisations, as in example 9 : 
9) The thing I like most about wearing abaya is that I do not have to worry about what I am wearing under it. I am $\underline{\text { able to }}(+\mathrm{ve})$ wear what I like.

Capacity focused on the writer's agency in selecting the qualities of the abaya in $52=7.74 \%$ positive and $6=13.95 \%$ negative realisations, as in Example 10:

10) Abayas have so many styles, shapes and colours nowadays that you could $(+v e)$ just pick and choose which one fits you the best.

Capacity was attributed to the abaya in $41=6.10 \%$ positive and $9=20.93 \%$ of realisations, in in example 11 :

11) The Abaya can $(+v e)$ be worn day to night and you can $(+v e)$ wear it to professional meetings looking professional and appropriate.

Realisations of capacity suggest that young professional Saudi women view the abaya as enabling them in specific ways, including fashion, comfort and ease, and suitability to various social settings.

\subsection{Judgments: Social Esteem-Normality}

Judgments of Social esteem valorise the writer or speaker's own social network as an experiential environment, against which they test and adjudicate specific experiences encountered. The adjudication of normality in connecting the fashionable abaya to the woman's personality is seen in example 12 below.

12) Usually ( $+v e)$, one's ( $+v e)$ sense of fashion is a reflection of one's $(+v e)$ personality and the way they ( $+v e)$ express themselves is with different colors and trends.

Indefinite pronouns generalise an attribute to a general class of items (Kishimoto, 2000). Here, "one" and "they" combine with "Usually" to convey a view that it is widely or normally the case, that abaya fashion choices reflect personality, particularly in terms of colour and trends.

13) Abaya has a classic look and always in style.

14) I daily (+ve) try to match the colours on my abaya to the colour of my makeup, shoes, and bag, which for me serves as an interesting morning exercise.

Adverbs of frequency ("Usually" in 12, "always" in 13) use temporal and probabilistic meanings to convey a generic character for something, when this is in fact contingent on the speaker's personal experience (Cohen, 1999). The generic character claimed in 13, "classic", claims typicality for the abaya in terms of social status and aesthetics, intensifying the claim of normativity. By comparison, the writer in 14 reports only on her personal dressing rituals, which are for her a normal activity ("daily"). Negative realisations of normativity ("they always find a way to make me stumble on the stairs, and get stuck to rolling chairs") will be discussed below.

Participants' comments frequently attributed typicality to abaya designs, according to various specific social identities and contexts:

15) Many (+ve) women are now putting much effort into the creativity of designing both their daily (+ve) and formal abayas, as it is transitioning from a traditional (+ve) garment to a fashion necessity $(+v e)$.

16) Abayas are commonly (+ve) used to accentuate appearance and make one's typically $(+v e)$ dull plain black dress into a personalized textile. The addition of colors also fits with the social placement $(+v e)$ of the wearer. For instance, one (+ve) wearing a fashionable abaya at school would commonly $(+v e)$ use an opaque cloth with darker colors, however wearing such(-ve) an abaya at a wedding or an evening party would be irrational.

Example 15 distinguishes three kinds of abayas: everyday, formal, and traditional. Example 16 distinguishes five: everyday, personalised, fashionable, school, and wedding/party. Both writers view these distinctions as socially normal.

The sense of the abaya as design-diversified according to identity, role and context, and signifying conventional messages that suit others' expectations, was particularly evident in comments by medical students, who understood abayas as practical, as closing the gap between doctors and patients, but also as unhygienic and potentially undermining their professional identity:

17) Abayas are loose, comfortable clothes. Therefore, doctors can always $(+v e)$ put them on quickly when on call at a late hour and don't have time to get dressed.

18) They help to decrease white-coat syndrome $(+v e)$, because abayas and headscarves are considered as $(+v e)$ a traditional $(+v e)$ outfit. Thus, patients will be less intimidated and more relaxed. Hence, doctors will get more accurate readings for vital signs such as blood pressure and heart rate. 
19) Elderly patients will usually $(+v e)$ be more comfortable talking to doctors wearing Abaya and headscarf, since it indicates they are from the same culture.

20) One of the major(-ve) problems for doctors is exposure to germs within medical facilities. Wearing an Abaya acts as a filter, as doctors are constantly(-ve) exposed to germs.

Wearing the abaya in medical contexts accounted for most $(43 / 57=75.44 \%)$ negative judgments of normality:

21) It is not globally accepted(-ve) for a doctor or a nurse to replace the global(-ve) hospital dress codes(-ve) with abayas.

22) Doctors all over the world $(+v e)$ are known by their sacred $(+v e)$ white lab coat and not wearing one(-ve) would make the patient question the doctors' authenticity(-ve).

23) Wearing an abaya makes it difficult to differentiate(-ve) between patients and medical staff, which makes an unprofessional(-ve) impression. A lab coat with formal pants, scrubs, or a skirt underneath is much more suitable $(+v e)$ for a professional $(+v e)$ look.

Judgments of normality, positive and negative, comprised the third most-frequently realised subcategory. While young professional Saudi women understand the abaya primarily as a fashionable item of clothing based on its visual details, this data shows they also type-cast these visual features secondarily by their conventional suitability to social identities, activities, contexts and roles.

\subsection{Judgments: Social Sanction-Propriety}

Quality, capacity, and normality were frequently-realised both positively and negatively. Other subcategories were frequently-realised only positively, including propriety. Judgments of Social sanction reflect socially codified norms and values found in rules and regulations, laws, civic duties, religious creeds, expected behaviours, and the penalties given for failure to comply. While we might expect frequent realisations in this category, it received only about $5 \%$ of total realisations. Realisations of propriety show a complex understanding of the abaya within Saudi cultural traditions and religious values. Most realisations identified it as a cultural practice $(49=29.34 \%)$ rather than a religious duty $26=15.57 \%$ ).

24) Abaya that relates to fashion is helping women embrace the culture $(+v e)$ in a fashionable way.

25) Abaya was first wore for religious reasons $(+v e)$, but by time it also gained fashion.

Patterns of theme (initial position in a sentence) and rheme (development of the theme within the remainder of the sentence) indicate a writer's view of the most important ideas they want to convey (theme), and how they want to detail their meaning on that topic (rheme). Propriety was rarely ( $5=2.99 \%$ Judgment:Social sanction-propriety) the theme in this dataset.

26) The Abaya doesn't just fit in the Islamic dress code criteria(+ve), it's more than a mere fashion in the Arab countries. The Abaya is one of the most trending dresses these days.

In most cases fashion or the individual writer was the theme. This must reflect the task instructions to some degree, so we cannot say that young professional Saudi women are not focused on propriety as a significant issue. But in most cases, in this corpus, propriety occurred as rheme, detailing the meaning of the theme:

27) Nowadays, fashion is one if the most dominant trends. So, we as Arabs decided to be in track $(+v e)$ so we started designing our traditional(+ve) Abaya.

28) It is considered a fashion item, yet you would still be someone who is sticked to his religious beliefs $(+v e)$.

The issue of modesty, central to the propriety of the abaya as a garment, was clearly framed by participants as a failure of men, rather than an obligation of women:

29) Many men look at women in a demeaning(-ve) manner and see them only as the bodies they're in, which is where abayas come in handy.

30) Abaya symbolizes a barrier between men and women, in which it guards $(+v e)$ women from different types of harassment(-ve), especially in the unsegregated medical profession. It forces her colleagues at work, particularly men, to go past her outer appearance and focus on the women's intellectual capabilities.

The issue of objection to the legal obligation to wear the abaya was mentioned only twice ("not all people want to wear it"). The language of rights was used alongside that of obligation slightly more often ( $4=2.40 \%)$ :

31) Fashion designers and shops are offering abayas with a new twist. They now come in various styles, colors and using different flow fabrics, as long as they serve their purpose $(+v e)$, which is to cover $(+v e)$. Every single girl has the option to style her own design and style that she feels suits her comfort and defines her personality. We 
now have a strong belief $(+v e)$ that a girl should have the right $(+v e)$ to choose what to wear as long as it is not defying(-ve) the cultural rules.

Even more frequently-realised $(11=6.59 \%)$ was the social levelling function of the abaya:

32) Abayas do not show the standard of living of a person who wears it, you should not $(+v e)$ know whether they are poor or rich.

31) The prices of an Abaya are affordable and this would make people feel the same $(+v e)$ whether you are rich or poor.

Overall, the low incidence of realisations of propriety suggests that young professional Saudi women connect the abaya with personal rights, women's freedoms, and social ethics, more than with cultural rules or religious obligations, though task instructions may have kept frequency in this latter case artificially low. Also, positive and negative realisations of social esteem, or the values shared in one's social network, were realised about 6 times as frequently as social sanction.

\subsection{Other Frequently-Realised Subcategories}

Worth and pleasure were also frequently-realised positively. They are connected, in that positive valuations are cognitively-framed realisations of positive affective experiences, as may be seen in these examples:

32) Abaya represents the Muslim(+ve worth) women. So it has to represent her in a good(+ve) way.

33) Personally, I love(+ve pleasure) how I get to express and show my culture through wearing abaya every time I walk out the door.

The first of two subcategories frequently-realised negatively was Appreciations of reaction in the area of impact, again reworking emotion as aspects of the abaya itself. Three frequently-realised negative impacts were dark colours in the heat of summer $(43=38.05 \%)$, snagging $(27=23.89 \%)$ problems with ease of movement $(15=13.27 \%)$ and problems with cleanliness $(6=55.31 \%)$ :

34) Snagging(-ve) and catching(-ve) in purse zippers, chairs and anything remotely sharp and pointy.

35) The main setbacks(-ve) of wearing an abaya would be related to restriction(-ve) of movement, hindrance(-ve) of seating positions, and the nuisance of keeping one's sleeves clean(-ve) during eating.

Negative realisations of tenacity focused on similar issues:

36) They always(-ve) find a way to make me stumble on the stairs, get stuck to rolling chairs, and get stuck to everything in general.

37) Dark colors always(-ve) show any dirt that sticks on it.

These subcategories highlight young professional Saudi women's focus on the practical aspects of the abaya.

\section{Conclusion}

This study has reached four conclusions. First, young professional Saudi women are clearly positive about the abaya, specifically about the diverse array of fashionable qualities, the opportunities these offer to express the self, and the practical ability to layer an elegant look over comfortable clothes. Second, young professional Saudi women take the abaya as normal, valuing its design flexibility in differentiating women by personality and work role, and professional and leisure context, though medical students also support the lab coat and scrubs as appropriate workplace clothing for doctors. Third, they focus far more on these factors than on the abaya's propriety, even using the language of personal rights in regard to young women choosing the qualities of abayas for themselves. For them, the abaya's propriety is a matter of social ethics, individual rights, insisting on respectful treatment when treated objectionably by some men, and cultural identity more than religious obligation. They understand the fashionable qualities of the abaya primarily in terms of a diversity of perceptual qualities, but also in terms of feeling enabled, and fitting into socially normal activities, roles, and contexts, and cultural worth. Their dislikes - hot textiles in summer, snagging, hindrances to movement, and textiles that show dirt - reflect their tendency to assess the abaya as both fashionable and practical.

Finally, despite global political debates about Muslim women's dress, Saudi women are not debating their commitment to this style of dress. Nor do they voice concern about losing their culture through globalisation and consumerism. They understand themselves as enjoying fashion equally with comfort and practicability, while conforming to their cultural and religious heritage. This powerful combination makes it unlikely the abaya will disappear as a global garment. However, it seems that the rest of the world has not yet appreciated their point of view, or seen that there could be benefit in doing so. The semiotic sparkle Muslim women find in the abaya offers 
opportunities to the fashion industry, and beyond, for example in the area of accessories. The perception of abaya design as diversified according to various social roles, activities, contexts and identities offers a range of institutions and businesses opportunities to consider how to incorporate Muslim women into their look. The distinction between elegant cover and comfortable, even messy inner look offers ways to construct characters and scenarios in popular media. Exploring these meanings, in terms of viewers and reception, cultural insiders and outsiders, would present a more sophisticated understanding of Muslim women as characters, helping to build global understanding. Political discussions about the ideological meaning of abayas as Muslim women's dress should be informed by a more nuanced understanding of the abaya to Muslim women.

Limitations of this study include the possibility of self-censorship by participants. However, the positive-tonegative ratio of realisations, the overwhelming positive focus on the perceptual qualities of abayas, and the topical regularities within the negative realisations are too strong and regular for that to be likely. A more significant limitation is sample composition. Given the global diversity of Muslim societies, no single-country participant group can adequately represent Muslim women's views of their fashion choices. This could be remedied by further studies in other Muslim countries, and among Muslim women living in non-Muslim majority countries. The use of university students is both a strength and a limitation. Given the status of KSA within the Muslim world, these women will be trend-setters beyond KSA, as they are in the Gulf region (Abaza, 2007). Given the urbanised nature of Saudi society, they will likely assume this role at home. Yet undergraduates are known to be conservative. They will likely lag behind fashion trends, rather than reflecting or driving current attitudes within the design world. This could be remedied by using a demographically representative sample. However, this would still only represent the country from which sample participants were selected, leaving the problem of generalising to the global Muslim community. Finally, this study was not able to focus on the specific fashion qualities of abayas which young professional Saudi women respond positively and negatively to. This was due to the need to establish more generally what their stance towards the abaya was. Framing a prompt able to elicit attitude to the specific features, given great diversity of design details also presents a challenge. This is a viable area for further study.

Muslim women experience the abaya positively as a fashionable item of clothing. These participants also commented on western reception of the abaya: "Women wearing abayas in foreign countries face a lot of ridicules, bullying and harassment since they dress differently from the mainstream style in those countries." Globalisation will mean that all cultures are exposed to an increasing variety of styles. Diversity will entail some effort to accept the cultural meanings of specific dress items from within the community that wears them.

\section{Acknowledgements}

The author would like to thank Professor Christian Matthiessen for his kind support.

\section{References}

Abaza, M. (2007). Shifting Landscapes of fashion in Contemporary Egypt. Fashion Theory, 11(2/3), 281-289, http://dx.doi.org/10.2752/136270407X202817

Abdul-Muhmin, A. G., \& Umar, Y. A. (2007). Credit card ownership and usage behaviour in Saudi Arabia: The impact of demographics and attitudes toward debt. Journal of Financial Services Marketing, 12(3), 219-234, http://dx.doi.org/10.1057/palgrave.fsm.4760074

Abu Odeh, L. (1993). Post-Colonial Feminism and the Veil: Thinking the Differenc. Feminist Review, 43(Spring), 26-37. http://dx.doi.org/10.2307/1395067

Ajrouch, K. J. (2007). Global contexts and the veil: Muslim integration in the United States and France. Sociology of Religion, 68(3), 321-325. Retrieved from http://www.jstor.org/stable/20453167

Al-Ashban, A. A., \& Burney, M. A. (2001). Customer adoption of tele-banking technology: the case of Saudi Arabia. International Journal of Bank Marketing, 19(5), 191-201. http://dx.doi.org/10.1108/0265232011 0399683

Al-Kahtani, N, Ryan, J. , \& Jefferson, T. (2006). How Saudi female faculty perceive internet technology usage and potential. Information Knowledge System Management, 5(4), 227-243.

Al-Meshal, S., \& Almotairi, M. (2013). Consumer Acceptance of Mobile Marketing: An Empirical Study on the Saudi Female. International Journal of Marketing Studies, 5(5), 94-100.

Al-Qasimi, N. (2010). Immodest modesty: Accommodating dissent and the abaya-as-fashion in the Arab Gulf states. Journal of Middle East Women's Studies, 6(1), 46-74. http://dx.doi.org/10.2979/MEW.2010.6.1.46

Alsharekh, A. (2008). Popular Culture and Political Identity in the Arab Gulf States. Saqi Books, London. 
Arthur, L. B. (1999). Religion, dress and the body. Oxford; New York, Berg

Attfield, J. (2000). Wild Things: The Material Culture of Everyday Life. Oxford, Berg.

Barnard, M. (2002). Fashion as communication. London, Routledge.

Barnes, R., \& Eicher, J. B. (Eds.) (1992). Dress and Gender: Making and Meaning in Cultural Contexts. Oxford, Berg.

Barthes, R. (2006). The Language of Fashion. In A. Stafford, \& M. Carter (Eds.). Sydney, Power Publications.

Bednarek, M. (2006). Polyphony in Appraisal: Typological and topological perspectives. Linguistics and the Human Sciences, 3(2), 107-136.

Bednarek, M. (2009). Dimensions of evaluation: Cognitive and linguistic perspectives. Pragmatics and Cognition 17(10), 146-175. http://dx.doi.org/10.1075/pc.17.1.05bed

Block, D. (1998). Exploring interpretations of questionnaire items. System, 26(3), 403-25. http://dx.doi.org/10. 1016/S0346-251X(98)00022-0

Breward, C. (2003). Fashion. Oxford University Press, Oxford.

Bullock, K. (2002). Rethinking Muslim women and the veil: Challenging historical and modern stereotypes. Herndon, VA: International Institute of Islamic Thought.

Saudi Arabia Central Department of Statistics and Information (CDSI). (2007). Distribution of disposable income in Saudi Arabia. Riyadh, Saudi Arabia: Ministry of Planning and National Economy, CDSI.

Cohen, A. (1999). Generics, frequency adverbs, and probability. Linguistics and philosophy, 22(3), 221-253. http://dx.doi.org/10.1023/A:1005497727784

Coleridge, N. (1989). The fashion conspiracy. London, Random House.

Craik, J. (2003). The face of fashion: Cultural studies in fashion. London, Routledge.

Crane, D. (2000). Fashion and Its Social Agendas: Class, Gender and Identity in Clothing. Chicago: University of Chicago Press.

Crossley, N. (2001). The social body: Habit, identity and desire. Sage, London.

Economist Intelligence Unit. (2002). EIU Country Report: Saudi Arabia, London, The Economist Group.

Eggins, S. (1994). An introduction to systemic functional linguistics. London, Pinter.

Eggins, S., \& Slade, D. (1997). Analysing Casual Conversation. London, Cassell.

Elfenbein, H. A., \& Ambady, N. (2002). On the universality and cultural specificity of emotion recognition: a meta-analysis. Psychological Bulletin, 128(2), 203-235. Retrieved from http://ambadylab.stanford.edu/pubs/ 2002ElfenbeinMeta.pdf

El-Guindi, F. (1999). Veil: Modesty, Privacy and Resistance, Dress, Body and Culture Series, Oxford and New York, Berg.

Fontaine, J. R., Scherer, K. R., \& Soriano, C. (Eds.). (2013). Components of emotional meaning: A sourcebook. OUP Oxford.

Forstenlechner, I., \& Rutledge, E. J. (2011). The GCC's demographic imbalance: perceptions, realities and policy options. Middle East Policy, 18(4), 25-43. http://dx.doi.org/10.1111/j.1475-4967.2011.00508.x

Garot, R., \& Katz, J. (2003). Provocative looks: Gang appearance and dress codes in an inner-city alternative school. Ethnography, 4(3), 421-454.

Gole, N. (2002). Islam in Public: New Visibilities and New Imageries. Fashion Theory, 14(1), 173-190. Retrieved from http://muse.jhu.edu/article/26271

Halliday, M. (1994). An Introduction to Functional Grammar. London, Edward Arnold.

Halliday, M. A. K., \& Matthiessen, C. (2004). An introduction to functional grammar (3rd ed.). Great Britain. Hodder Education.

Kadivar, M. (2003). An Introduction to the Public and Private Debate in Islam. Social Research, 70(3), 659-680. http://www.jstor.org/stable/40971634

Kaiser, S. B. (1997). The Social Psychology of Clothing: Symbolic Appearances in Context (Revised 2nd ed.). New York: Fairchild Publications. 
Khraim, H. S. (2011). The influence of brand loyalty on cosmetics buying behaviour of UAE female consumers. International Journal of Marketing Studies, 3(2), 123-133. http://dx.doi.org/10.5539/ijms.v3n2p123

Kishimoto, H. (2000). Indefinite pronouns and overt N-raising. Linguistic Inquiry, 31(3), 557-566, http://dx.doi.org/10.1162/002438900554451

Kuppens, P., Van Mechelen, I., Smits, D. J. M., De Boeck, P., \& Ceulemans, E. (2007). Individual differences in patterns of appraisal and anger experience. Cognition and Emotion, 21(4), 689-713. http://dx.doi.org/10. 1080/02699930600859219

Lewis, R. (2015). Muslim fashion: contemporary style cultures. Durham and London, Duke University Press.

Lindholm, C. (2013). Cultural collision: The branded abaya. Fashion, Style and Popular Culture, 1(1), 45-55. https://doi.org/10.1386/fspc.1.1.45_1

Lindholm, C. (2010). Invisible No More: The Embellished Abaya in Qatar. Textile Society of America Symposium Proceedings. Paper 34. Retrieved from http://digitalcommons.unl.edu/tsaconf/34

Lindholm, C. (2014). Visible status: Couture and designer abayas. Global Fashion Brands: Style, Luxury and History, 1(1), 153-164. https://doi.org/10.1386/gfb.1.1.153_1

Maira, S. (2009). 'Good' and 'Bad' Muslim Citizens: Feminists, Terrorists and US Orientalisms'. Feminist Studies, 35(3), 631-656. Retrieved from http://www.jstor.org/stable/40608397

Martin, J.R. (1995). Interpersonal meaning, persuasion and public discourse: Packing semiotic punch. Australian Journal of Linguistics, 15(1), 33-67. http://dx.doi.org/10.1080/07268609508599515

Martin, J. R., \& Rose, D. (2003). Working with discourse: meaning beyond the clause. London, Continuum.

Martin, J., \& White, P. ( 2005). The Language of Evaluation: Appraisal in English. New York, Palgrave.

Meer, N., Dwyer, C., \& Modood, T. (2010). Embodying Nationhood? Conceptions of British national identity, citizenship, and Gender in the Veil Affair. Sociological Review, 58(1), 84-111. http://dx.doi.org/10.1111/ j.1467-954X.2009.01877.x

Moors, A. (2007). Fashionable Muslims: Notions of Self, Religion, and Society in Sana'a. Fashion Theory, 11(2/3), 319-346. http://dx.doi.org/10.2752/136270407X202853

Morris, P. (2006). Gender in print advertisements: A snapshot of representations from around the world. Media Report to Women, 34(3), 13-20. Retrieved from http://ecommons.luc.edu/cgi/viewcontent.cgi?article $=1016 \&$ amp;context $=$ communication_facpubs

O'Donnell, M. (2008). Demonstration of the UAM CorpusTool for text and image annotation. Proceedings of the 46th Annual Meeting of the Association for Computational Linguistics on Human Language Technologies: Demo Session. Association for Computational Linguistics.

Pang, B., \& Lee, L. (2008). Opinion mining and sentiment analysis. Foundations and trends in information retrieval, 2(1-2), 1-135. http://dx.doi.org/10.1561/1500000011

Pang, B., Lee, L., \& Vaithyanathan, S. (2002). Thumbs up? Sentiment classification using machine earning techniques. Proceedings of the 2002 conference on empirical methods in natural language processing. Philadelphia, Pennsylvania, USA. http://dx.doi.org/10.3115/1118693.1118704

Panther, K.U., \& Thornburg, L. (1999). The potentiality for actuality metonymy in English and Hungarian. In K. Panther, \& G. Raggen (Eds.), Metonymy in language and thought (pp. 333-351). Amsterdam, John Benjamins.

Pavlenko, A. (2002). Bilingualism and emotions. Multilingua, 2l(1), 45-78, https://doi.org/10.1515/ mult.2002.004

Purdy, D. (2004). The rise of fashion: A reader. Minneapolis, MN, University of Minnesota Press.

Ramanathan, V., \& Kaplan, R. (2000). Genres, authors, discourse communities: theory and application for L1 and L2 writing instructors. Journal of Second Language Writing, 9(2), 171-191. http://dx.doi.org/10.1016/S1060 $-3743(00) 00021-7$

Rambo, K., Liu, K., \& Nakata, K. (2009). The socio-cultural factors influencing online female consumers in Saudi Arabia. Computational Science and Engineering, 2009. CSE'09. International Conference on (Vol. 4) IEEE, 633-638.

Rashad, H. (2000). Demographic transition in Arab countries: A new perspective. Journal of Population Research, 17(1), 83-101. http://dx.doi.org/10.1007/BF03029449 
Read, J., \& Carroll, J. (2012). Annotating expressions of appraisal in English. Language resources and evaluation, 46(3), 421-447. http://dx.doi.org/10.1007/s10579-010-9135-7

Sadi, M. A., \& Saricimen, T. (2010). Value factors determining consumer satisfaction at full-scale restaurants in Saudi Arabia. Journal for Global Business Advancement, 3(4), 285-294. http://dx.doi.org/10.1504/ JGBA.2010.036034

Saudi Arabia Communication and Information Technology Commission. (2008). Internet Usage in the Kingdom of Saudi Arabia: Individuals. Retrieved November 10, 2015, from www.citc.gov.sa

Scherer, K. R., Schoor, A., \& Johnstone, T. (Eds.). (2001). Appraisal processes in emotion: Theory, methods, research. Canary, Oxford University Press.

Siraj, A. (2011). Meanings of modesty and the hijab amongst Muslim women in Glasgow, Scotland. Gender, Place and Culture, 18(6), 716-731. http://dx.doi.org/10.1080/0966369X.2011.617907

Sobh, R., Belk, R., \& Gressel, J. (2008). The scented winds of change: conflicting notions of modesty and vanity among young Qatari and Emirati women. Advances in Consumer Research, 8(1), 342-343. Retrieved from http://www.acrwebsite.org/volumes/v37/acr_v37_14950.pdf

Stack, G. J. (2012). The language of possibility and existential possibility. The Modern Schoolman, 50(2), 159182. http://dx.doi.org/10.5840/schoolman19735026

Thompson, G. (2004). Introducing functional grammar. Great Britain. Hodder Education.

Turney, P. D. (2002). Thumbs up or thumbs down? Semantic orientation applied to unsupervised classification of reviews. Proceedings of the $40^{\text {th }}$ Annual meeting of the Association for Computational Linguistics. Philadelphia, PA, USA, 417-424.

Williamson, M. (2014). The British Media, the Veil and the Limits of Freedom. Middle East Journal of Culture and Communication, 7(1), 64-81. http://dx.doi.org/10.1163/18739865-00701005

Wurm, L., \& Vakoch, D. (1996). Dimensions of speech perception: Semantic associations in the affective lexicon. Cognition and Emotion, 10(4), 409-423. http://dx.doi.org/10.1080/026999396380204

Yang, C., Lin, K. H., \& Chen, H. H. (2007). Building emotion lexicon from weblog corpora. Proceedings of the ACL 2007 demo and poster sessions. Prague, Czech Republic, 133-136.

Zamberi, A. (2011). Evidence of the characteristics of women entrepreneurs in the Kingdom of Saudi Arabia: An empirical investigation. International Journal of Gender and Entrepreneurship, 3(2), 123-143, http://dx.doi.org/10.1108/17566261111140206

Zine, J. (2006). Unveiled sentiments: Gendered Islamophobia and experiences of veiling among Muslim girls in a Canadian Islamic school. Equity and Excellence in Education, 39(3), 239-252. http://dx.doi.org/10.1080/ 10665680600788503

\section{Copyrights}

Copyright for this article is retained by the author(s), with first publication rights granted to the journal.

This is an open-access article distributed under the terms and conditions of the Creative Commons Attribution license (http://creativecommons.org/licenses/by/4.0/). 